\title{
Comparative Synthesis and Cyclization of 1, 5-Diketone
}

\section{Abstract}

Diketones are found to be extremely reactive due to owing electron deficient carbon atoms of double carbonyls groups and are extensively used for huge range of organic synthesis such as tetracyclones, triazines, inidazoles, quinoxalines, pyrazinones, peroxides, Photoluminescent compounds, cis-jasmone, furan, pyrroles and thiophenes etc. 1, 5-diketone (1, 3, 5-triphenyl-1, 5-pentanedione) has been synthesized by the condensation of acetophenone and benzaldehyde at different reaction conditions while stirring at $25^{\circ} \mathrm{C}$. Further, the synthesized 1,3 , 5-triphenyl-1, 5-pentanedione has been condensed with benzil and also cyclized in acidic as well as in basic media to get the product. The progress of reaction was monitored by TLC (thin layer chromatography, Eluent; $n$-hexane/ethylacetate) visualizing under UV lamp and lodine bath.

Keywords: Diketones; Synthesis; Condensation; Photoluminescent

Received: November 29, 2019; Accepted: December 16, 2019; Published: December 23, 2019

\section{Introduction}

Diketones play a very important role in the synthesis of organic chemistry. They possess amazingly chemical properties due to highly reactive carbonyl groups. A number of strategies have been employed for the synthesis of diketones such as carbonmonoxide insertion into carbon-lithium bonds [1], light induced $\mathrm{C}=\mathrm{C}$ bond cleavage of Enanimones [2], oxidatisve coupling of imidazo $[1,2]$ pyridines and methyl ketones [3-5], soft enolization of ketones [7,8], $\alpha$-halo ketones and TDAE [9], Methyl ketones and $\alpha$-bromo ketones $[10,11]$, unsymmetrical disubstituted acetylene by mercuric ion catalysis [12], enol esters and ketones in manganic acetate $[13,14]$, alkyl copper reagents and conjugated enones $[15,16]$, silylenolethers $[17,18]$, dimerization of ketone enolates [19-21], nito-olefins [22], nitro alkanes [23], organometallic compounds [24], methyl ketone carbanions and $\alpha$-ketoketenedithioacetals [25] and birch reduction [26]. 1, 5diketone owing to electrophilic centers of two carbonyl groups has significant importance as an intermediate in the synthesis of many heterocyclic $[27,28]$ and polyfuntional $[29,30]$. Working on the methodology of Hirsh and Bailey [31] acetophenone and benzaldehyde were condensed in the presence of sodium hydroxide and ethanol to synthesize 1, 3, 5-triphenyl-1, 5-pentanedione 3. Later on, same reaction was carried out at different reaction conditions for comparative yield. Next 1, 3, 5-triphenyl-1, 5-pentanedione was condensed with benzil and cyclized as well in acidic and basic media.

\section{Syeda Shaista Gillani* and Ambreen Mushtaq}

Department of Chemistry, Lahore Garrison University, DHA Phase-VI, P.O. Box. No. 54792, Lahore, Pakistan

*Corresponding author: Syeda Shaista Gillani

” shaistagillani@lgu.edu.pk

Department of Chemistry, Lahore Garrison University, DHA Phase-VI, P.O. Box. No. 54792, Lahore, Pakistan

Tel: +9242-37181821-22-Ex-431

Citation: Syeda Shaista Gillani, Ambreen Mushtaq. Comparative Synthesis and Cyclization of 1, 5-Diketone. J Org Inorg Chem. 2019, 5:2.

\section{Experimental}

\section{Materials}

All reagents were obtained from commercial sources and were used without purification unless otherwise stated. $\mathrm{CH}_{2} \mathrm{Cl}_{2}$ (DCM) was dried over $\mathrm{CaH}_{2}$ and freshly distilled before use. Tetrahydrofuran (THF) for preparation of DSs was distilled with $\mathrm{NaHSO}_{3}$ and 3,5-ditert-butyl-4-hydroxytoluene (BHT) and restored in the dark. Solvents and reagents were deoxygenated when necessary by purging with $\mathrm{N}_{2}$.

\section{Techniques}

${ }^{1} \mathrm{H}$ NMR spectra were recorded at $500 \mathrm{MHz}$, on a Bruker DRX (500) NMR spectrometer. All NMR spectra were measured at $23^{\circ} \mathrm{C}$ in $\mathrm{CDCl}_{3}$. Chemical shifts $(\delta)$ are reported in ppm, and coupling constants $(\mathrm{J})$ are reported in hertz $(\mathrm{Hz})$. The resonance multiplicities in the ${ }^{1} \mathrm{H}$ NMR spectra are described as " $\mathrm{s}$ " (singlet), " $\mathrm{d}$ " (doublet), " $\mathrm{t}$ " (triplet), and " $\mathrm{m}$ " (multiplet). Residual protic solvent of $\mathrm{CDCl}_{3}(1 \mathrm{H}, \delta 7.26 \mathrm{ppm})$ or tetramethylsilane (TMS) was used as the internal reference in the ${ }^{1} \mathrm{HNMR}$ spectra. Evolution of the reaction was monitored by thin-layer chromatography (TLC) using silica gel precoated plates (E. Merck) and compounds were visualized by UV light with a wavelength of $254 \mathrm{~nm}$. Purifications by flash column chromatography were performed using flash silica gel from Silicycle $(60 \AA, 40-63 \mu \mathrm{m})$ with the indicated eluent. The purity of the products was determined by a combination of TLC, and high-pressure liquid chromatography (HPLC) was 
carried out using a Shimadzu LC-20 AD high-performance liquid chromatograph pump, PE Nelson Analytical 900 Series integration data station, Shimadzu RID-10 A refractive index(RI) detector, Shimadzu SPD-10A VP (UV-vis), and three AM gel columns (a guard column, two $500 \AA$, $10 \mu \mathrm{m}$ columns). THF was used as solvent at the oven temperature of $23^{\circ} \mathrm{C}$. Detection was done by UV absorbance at $254 \mathrm{~nm}$. The accurate mass measurement of the synthesized compounds was done on (LC-MS) Liquid chromatography - mass spectrometry.

Synthesis of 1,5-diketone from acetophenone and benzaldehyde with sodium hydroxide: Benzaldehyde $(570 \mathrm{mmol})$ and acetophenone (1500 mmol) was dissolved to a solution of ethanol $(10 \mathrm{ml})$ and sodium hydroxide was added. The reaction mixture was refluxed for 15 minutes with stirring. The progress of reaction was checked by TLC (thin layer chromatography). After the completion of reaction it was allowed to cool down to $25^{\circ} \mathrm{C}$ and diluted with distilled water $(50 \mathrm{ml})$. It was kept in freezer overnight. Deep orange oil settled or deposited to the bottom of the vessel and separated. Cold methanol $(10 \mathrm{ml})$ was added to the orange oil to obtain the white product. Purification was done by recrystallization (ethanol/n-hexane) to afford pure compound $\left(5.98 \mathrm{~g}, 73 \%\right.$ yield) as a white crystal, m.p $=82-85^{\circ} \mathrm{C} .{ }^{1} \mathrm{H}$ NMR $(500$ $\mathrm{MHz}, \mathrm{CDCl} 3) 6.62-7.39 \mathrm{~m} \mathrm{15H}, 3.513 \mathrm{~d} 2 \mathrm{H} ;{ }^{13} \mathrm{C}$ NMR $(126 \mathrm{MHz}$, $\mathrm{CDCl}_{3}$ ) 49.4, 126.41, 127.48, 128.04, 128.34, 128.54, 129.35, $130.54,130.66,131.12,140.63,140.66,143.03$; IR (neat) 3028, 1684, 1287, $687 \mathrm{~cm}-1$; UV-VIS; $\lambda_{\max }\left(\mathrm{CH}_{2} \mathrm{Cl} 2 / \mathrm{nm}\right)=230,260 \mathrm{~nm}$; LC-MS ES $(\mathrm{m} / \mathrm{z}):[\mathrm{M}+\mathrm{H}]^{+} 329.25$.

Synthesis of 1, 5-diketone from acetophenone and benzaldehyde with sodium ethoxide: Benzaldehyde $(570 \mathrm{mmol})$ and acetophenone (1500 mmol) was added to a solution of sodium ethoxide $(10 \mathrm{ml})$. The reaction was stirred at $25^{\circ} \mathrm{C}$ overnight. Then it was diluted with distilled water $(50 \mathrm{ml})$ and was kept in a freezer overnight. Organic layer was separated and washed with cold methanol. Crude product obtained and recrystallized in ethanol to afford pure compound $(6.79 \mathrm{~g}, 83 \%$ yield $)$ as a white crystal m.p $=82$ $85^{\circ} \mathrm{C}$.

Synthesis of 1, 5-diketone from acetophenone and benzaldehyde with sodium iso-Propoxide: Benzaldehyde $(570 \mathrm{mmol})$ and acetophenone (1500 mmol) was added to a solution of sodium iso-propoxide (10 $\mathrm{ml}$ ). The reaction was stirred at $25^{\circ} \mathrm{C}$ overnight. The completion of reaction was checked by thin layer chromatography (eluent: $\mathrm{n}$-hexane/ethyl acetate=9:1). The reaction mixture was diluted with distilled water $(50 \mathrm{ml})$. It was kept in a freezer overnight. Organic layer was separated and washed with cold methanol. Crude product was precipitated and filtered. Recrystallization was done in ethanol to afford pure product $(7.698,94 \%$ yield) as white crystals, $m \cdot p=82-85^{\circ} \mathrm{C}$.

Synthesis of 1, 5-diketone from acetophenone and benzaldehyde with sodium tert-Butoxide:

Benzaldehyde $(570 \mathrm{mmol})$ and acetophenone $(1500 \mathrm{mmol})$ was added to a solution of sodium $\mathrm{n}$-butoxide $(10 \mathrm{ml})$.The reaction was stirred at $25^{\circ} \mathrm{C}$ overnight. The progress of reaction was confirmed by thin layer chromatography (eluent: $n$-hexane/ethyl acetate=9:1). The reaction mixture was diluted with distilled water $(50 \mathrm{ml})$. It was kept in a freezer overnight. Organic layer was separated and washed with cold methanol. Crude product was precipitated and filtered. Recrystallization was done in ethanol to afford pure product $(7.45 \mathrm{~g}, 91 \%$ yield) as white crystals m. $\mathrm{p}=82$ $85^{\circ} \mathrm{C}$.

Synthesis of 1, 5-diketone from acetophenone and benzaldehyde with pyridine: Pyridine $(10 \mathrm{ml})$ was added to the mixture of benzaldehyde $(570 \mathrm{mmol}$ ) and acetophenone (1500 mmol). The reaction was stirred at $25^{\circ} \mathrm{C}$ overnight. The reaction mixture was diluted with distilled water $(50 \mathrm{ml})$. It was kept in a freezer overnight. Organic layer was separated and washed with cold methanol. Crude product obtained and filtered. Recrystallization was done in ethanol to afford pure compound $(6.715 \mathrm{~g}, 82 \%$ yield) as a white crystals $m \cdot p=82-85^{\circ} \mathrm{C}$.

Synthesis of 1, 5-diketone from acetophenone and benzaldehyde with piperidine: Piperidine $(10 \mathrm{ml})$ was added to the mixture of benzaldehyde $(570 \mathrm{mmol}$ ) and acetophenone (1500 mmol). The reaction was stirred at $25^{\circ} \mathrm{C}$ overnight. The reaction mixture was diluted with distilled water $(50 \mathrm{ml})$. It was kept in a freezer overnight. Organic layer was separated and washed with cold methanol. Crude product obtained and filtered. Recrystallization was done in ethanol to afford pure compound ( $7.45 \mathrm{~g}, 91 \%$ yield) as a white crystals $m \cdot p=82-85^{\circ} \mathrm{C}$.

Synthesis of 1, 5-diketone from acetophenone and benzaldehyde with pyrrolidine: Benzaldehyde $(570 \mathrm{mmol})$ and acetophenone (1500 mmol) was added to a solution of pyrrolidine $(10 \mathrm{ml})$. The reaction mixture was stirred at $25^{\circ} \mathrm{C}$ overnight. The completion of reaction was checked by thin layer chromatography (eluent: n-hexane/ethyl acetate=9:1). The reaction mixture was diluted with distilled water $(50 \mathrm{ml})$. It was kept in a freezer overnight. Organic layer was separated and washed with cold methanol. Crude product was precipitated and filtered. Recrystallization was carried out with ethanol to get pure product $(7.37 \mathrm{~g}, 92 \%$ yield) as white crystals $m . p=82-85^{\circ} \mathrm{C}$.

Synthesis of 1, 5-diketone from acetophenone and benzaldehyde with trimethyl amine: Trimethyl amine $(10 \mathrm{ml})$ was added to the mixture of benzaldehyde $(570 \mathrm{mmol}$ ) and acetophenone (1500 $\mathrm{mmol})$. The reaction mixture was stirred at $25^{\circ} \mathrm{C}$ overnight. It was then diluted with distilled water $(50 \mathrm{ml})$ and kept in a freezer overnight. Organic layer was separated and washed with cold methanol. Crude product obtained and filtered. Recrystallization was done in ethanol to afford pure compound ( $7.61 \mathrm{~g}, 93 \%$ yield) as a white crystals, $\mathrm{m} \cdot \mathrm{p}=82-85^{\circ} \mathrm{C}$.

Synthesis of 1, 5-diketone from acetophenone and benzaldehyde with methyl amine: Benzaldehyde $(570 \mathrm{mmol})$ and acetophenone (1500 mmol) was added to a solution of methyl amine $(10 \mathrm{ml})$. The reaction mixture was stirred at $25^{\circ} \mathrm{C}$ overnight. The progress of reaction was confirmed by thin layer chromatography (eluent: n-hexane/ethyl acetate=9:1). The reaction mixture was diluted with distilled water $(50 \mathrm{ml})$. It was kept in a freezer overnight. Organic layer was separated and washed with cold methanol. Crude product was precipitated and filtered. Recrystallization was done in ethanol to afford pure product $(7.45 \mathrm{~g}, 91 \%$ yield) as white crystals m. $p=82-85^{\circ} \mathrm{C}$. 
Synthesis of methanone, 4, 5-diphenyl-3, 5-cyclopentadiene [diily]diphenoneatreflux in basic media: Benzil (4, $1 \mathrm{mmol}$ ) was added to a solution of 1, 3, 5-triphenyl-1, 5-pentane-dione (1 mmol) in ethanol $(10 \mathrm{ml})$ and $\mathrm{KOH}(0.69 \mathrm{mmol})$. The reaction mixture was refluxed. Thin layer chromatography was used to monitor the progress of reaction. After the reaction was completed, the reaction mixture was cooled down to $0^{\circ} \mathrm{C}$ and precipitates appeared and collected as crude product. To purify the crude product silica gel chromatography was done (eluent: $n$-hexane/ ethyl acetate=9:1) to afford 1, 2, 4-triphenyl-1, 3-cyclopentadiene $6(0.031 \mathrm{~g}, 23 \%$ yield) and a yellow solid of Methanone, 4, 5-diphenyl-3, 5-cyclopentadiene-[diily]-diphenone5 (0.096 g, $71 \%$ yield), m.p $=200^{\circ} \mathrm{C} .{ }^{1} \mathrm{H} \mathrm{NMR}(500 \mathrm{MHz}, \mathrm{CDCl} 3) 7.46-8.42 \mathrm{~m}$ $20 \mathrm{H}, 1.902 \mathrm{H} ;{ }^{13} \mathrm{C}$ NMR (126 MHz, CDCl3) 126.41, 127.48, 128.04, 128.34, 128.54, 129.35, 130.54 130.66, 131.12, 140.63, 140.66, 143.03; IR (neat) 3004, 1620, 1492, $763 \mathrm{~cm}-1$; LC-MS ES $(\mathrm{m} / \mathrm{z})$ : $[\mathrm{M}+\mathrm{H}]^{+} 427.12$.

Synthesis of methanone, 4, 5-diphenyl-3, 5-cyclopentadiene [diily]diphenone 5 on stirring in basic media: Benzil $(1 \mathrm{mmol})$ was added to a solution of 1, 3, 5-triphenyl-1, 5-pentane-dione (1 mmol) in sodium ethoxide $(10 \mathrm{ml})$. The reaction mixture was stirred overnight. Thin layer Chromatography was used to confirm the progress of reaction. After the reaction was completed, the reaction mixture was cooled down to an ice bath. Precipitates appeared and collected as crude product. To purify the crude product silica gel column chromatography was done eluent: n-hexane/ethyl acetate $=9: 1)$ to get the product $6(0.016 \mathrm{~g}, 12 \%)$ and yellow solids $5(0.106 \mathrm{~g}, 78 \%$ yield $), \mathrm{m} . \mathrm{p}=200^{\circ} \mathrm{C}$.

Synthesis of methanone, 4, 5-diphenyl-3, 5-cyclopentadiene [diily]diphenone in acidic media while stirring: Conc. $\mathrm{H}_{2} \mathrm{SO}_{4}(10 \mathrm{ml})$ was added to the mixture of benzil $(1 \mathrm{mmol})$ and $1,3,5$-triphenyl-2, 5 -pentanedione $(1 \mathrm{mmol})$. The reaction mixture was refluxed. The progress of reaction was tracked by thin layer Chromatography. After the reaction was completed, the reaction mixture was cooled down to an ice bath precipitates appeared and collected as crude product. Purification was done by silica gel column chromatography eluent; ethylacetate: n-hexane) to afford a cyclized product $6(0.06 \mathrm{~g}, 7 \%)$ and a yellow solid $\mathbf{5}(0.126 \mathrm{~g}, 93 \%$ yield), $m . p=200^{\circ} \mathrm{C}$.

Synthesis of methanone, 4, 5-diphenyl-3, 5-cyclopentadiene [diily]diphenone in acidic media while stirring: Conc. $\mathrm{H}_{2} \mathrm{SO}_{4}(10 \mathrm{ml})$ was added to the mixture of benzil ( $1 \mathrm{mmol})$ and $1,3,5$-triphenyl-2, 5 -pentanedione $(1 \mathrm{mmol})$. The reaction mixture was refluxed. The progress of reaction was tracked by thin layer Chromatography. After the reaction was completed, the reaction mixture was cooled down to an ice bath precipitates appeared and collected as crude product. Purification was done by silica gel column chromatography eluent; ethylacetate: n-hexane) to afford a cyclized product $6(0.06 \mathrm{~g}, 7 \%)$ and a yellow solid $5(0.126 \mathrm{~g}, 93 \%$ yield), $m . p=200^{\circ} \mathrm{C}$.

Synthesis of methanone, 4, 5-diphenyl-3, 5-cyclopentadiene [dilly]diphenonein acidic media under reflux: Reaction between 1, 3, 5-triphenyl-1, 5-pentanedione (1 mmol) and conc. $\mathrm{H}_{2} \mathrm{SO}_{4}(10 \mathrm{ml})$ was carried on 15 minutes reflux. Thin layer chromatography was used to check the progress of reaction. After the reaction was completed, the reaction mixture was cooled down to $0^{\circ} \mathrm{C}$ and precipitates appeared. Filtration was done to collect the residue. It was then purified via silica gel thin layer column chromatography eluent: $n$-hexane/ethyl acetate=9:1] to get a pure yellow solids 5 $\left(0.11 \mathrm{~g}, 82 \%\right.$ yield), m.p $=200^{\circ} \mathrm{C}$.

\section{Results and Discussion}

Diketones are found to be extremely reactive due to owing electron deficient carbon atoms of double carbonyls groups and are extensively used for huge range of organic synthesis such as tetracyclones, triazines, imidazoles, quinoxalines, pyrazinones, peroxides, photoluminescent compounds, cis-jasmone, furan, pyrroles and thiophenes (Figure 1).

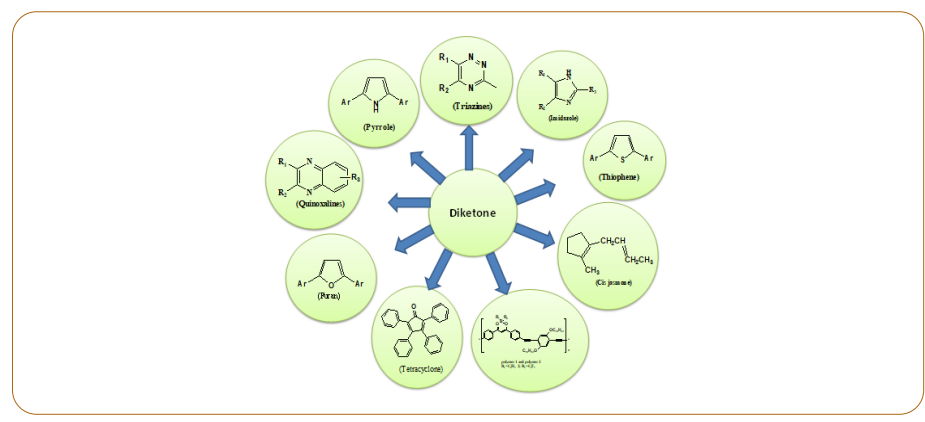

\section{Figure 1 Applications of Diketone.}

1, 3, 5-triphenyl-1, 5-pentanedione 3 has been synthesized on stirring under different reaction conditions and yield is compared with the reported method. A number of inorganic and organic (aliphatic and aromatic) bases such as sodium ethoxide, sodium iso-propoxide, sodium n-butoxide, sodium tertiary butoxide, piperidine, pyrrolidine, trimethyl-amine, methyl-amine and pyridine have been used for comparative yield on stirring. The strategy employed for the synthesis of 1, 3, 5-triphenyl-1, 5-pentanedione $\mathbf{3}$ was the condensation of acetophenone $\mathbf{2}$ and benzaldehyde 1 (Scheme 1).

Scheme 1: General Strategy for the synthesis of 1, 3, 5-triphenyl-1, 5-pentanedione.

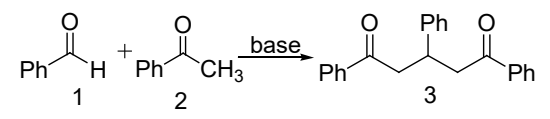

Bases $=$ Sodium Ethoxide, Sodium iso-Propoxide, Sodium n-Butoxide, Sodium tertiary Butoxide, Piperidine, Pyrrolidine, Trimethyl-amine, Methyl-amine and Pyridine

The medium adopted for the condensation to afford 1, 3, 5-triphenyl-1, 5-pentanedione 3 was basic (Figure 2).

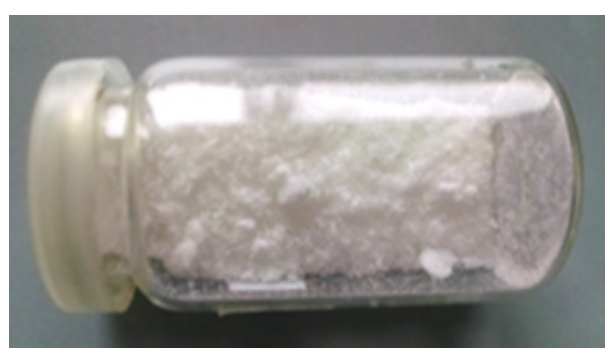

Figure 2 1, 3, 5-triphenyl-1, 5-pentanedione.

The progress of reaction was monitored by thin layer chromatography (Eluent; n-hexane/ethylacetate=3:1). The synthesized compounds were visualized under $254 \mathrm{~nm}$ UV lamp and lodine bath. When the reaction was conducted with pyridine 
as a base, $82 \%$ yield was obtained while with methylamine (base) the yield was $95 \%$. The difference in yields was found due to the different pka values. Lesser the pka value, stronger the base will be. Reaction with sodium ethoxide, sodium iso-propoxide, Sodium tert-butoxide, n-butoxide, piperdine, pyrrolidine and trimethylamine gave rise $83 \%, 87 \%, 94 \%, 91 \%, 91 \%, 92 \%$ and $93 \%$ yield respectively (Table 1 ). Characterization of the product was done by LC-MS, GC-MS, IR, ${ }^{13}$ CNMR and ${ }^{1} \mathrm{HNMR}$.

Table 1: Summarized results for the synthesis of 1, 3, 5-triphenyl-1, 5-pentan-dione.

\begin{tabular}{|c|c|c|c|c|c|}
\hline & Reactant 1 & Reactant 2 & Bases & Stirring & $\begin{array}{l}\text { Yield } \\
\text { (\%) } 3\end{array}$ \\
\hline 1 & benzaldehyde & acetophenone & $\begin{array}{l}\text { sodium } \\
\text { ethoxide }\end{array}$ & $\begin{array}{l}\text { overnight, } \\
25^{\circ} \mathrm{C}\end{array}$ & $83 \%$ \\
\hline 2 & benzaldehyde & acetophenone & $\begin{array}{l}\text { sodium } \\
\text { iso- } \\
\text { propoxide }\end{array}$ & $\begin{array}{l}\text { overnight, } \\
25^{\circ} \mathrm{C}\end{array}$ & $87 \%$ \\
\hline 3 & benzaldehyde & acetophenone & $\begin{array}{l}\text { sodium } \\
\text { t-butoxide }\end{array}$ & $\begin{array}{l}\text { overnight, } \\
25^{\circ} \mathrm{C}\end{array}$ & $94 \%$ \\
\hline 4 & benzaldehyde & acetophenone & $\begin{array}{l}\text { sodium } \\
\text { n-butoxide }\end{array}$ & $\begin{array}{l}\text { overnight, } \\
25^{\circ} \mathrm{C}\end{array}$ & $91 \%$ \\
\hline 5 & benzaldehyde & acetophenone & pyridine & $\begin{array}{l}\text { overnight, } \\
25^{\circ} \mathrm{C}\end{array}$ & $82 \%$ \\
\hline 6 & benzaldehyde & acetophenone & piperidine & $\begin{array}{l}\text { overnight, } \\
25^{\circ} \mathrm{C}\end{array}$ & $91 \%$ \\
\hline 7 & benzaldehyde & acetophenone & pyrrolidine & $\begin{array}{l}\text { overnight, } \\
25^{\circ} \mathrm{C}\end{array}$ & $90 \%$ \\
\hline 8 & benzaldehyde & acetophenone & $\begin{array}{l}\text { trimethyl- } \\
\text { amine }\end{array}$ & $\begin{array}{l}\text { overnight, } \\
25^{\circ} \mathrm{C}\end{array}$ & $93 \%$ \\
\hline 9 & benzaldehyde & acetophenone & $\begin{array}{l}\text { methyl- } \\
\text { amine }\end{array}$ & $\begin{array}{l}\text { overnight, } \\
25^{\circ} \mathrm{C}\end{array}$ & $95 \%$ \\
\hline
\end{tabular}

In the second step 1, 3, 5-triphenyl-1, 5-pentanedione $\mathbf{3}$ was condensed with benzil 4 to afford condensed product methanone, 4,5-diphenyl-3,5-cyclopentadiene-[diiyl]-diphenone 5 and cyclized product 1, 2, 4-triphenyl 1, 3-cyclopentadiene 6 (Scheme 2).

Scheme 2: General strategy for the synthesis of methanone, 4, 5-diphenyl-3, 5-cyclopentadiene [diiyl]-diphenone (5) and 1, 2, 4-triphenyl 1, 3-cyclopentadiene (6)

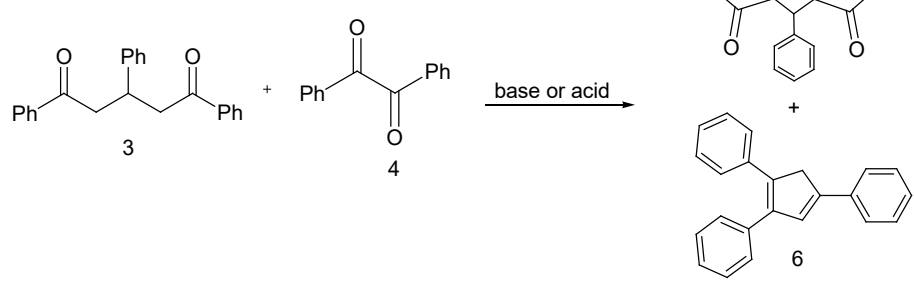

Condensation with $\mathrm{KOH}, \mathrm{C}_{2} \mathrm{H}_{5} \mathrm{OH}$ Prompt $71 \%$ and $23 \%, 78 \%$ and $12 \%$ with sodium ethoxide and $93 \%, 70 \%$ with Conc. $\mathrm{H}_{2} \mathrm{SO}_{4}$. When the compound 1, 3, 5-triphenyl-1, 5-pentanedione 3 was allowed to cyclize in Conc. $\mathrm{H}_{2} \mathrm{SO}_{4}$, the spot (exactly like 6) was observed in thin layer chromatography. It was crystallized and collected with $82 \%$ yield. Its solution was found to be fluorescent under UV lamp. The characterization of 5 was done with ${ }^{1} \mathrm{HNMR}$ and ${ }^{13} \mathrm{CNMR}$. The results for the synthesis of methanone, 4, 5-diphenyl-3, 5-cyclopentadiene-[diily]-diphenone are Summarized (Table 2).

\section{Conclusion}

1, 3, 5-triphenyl-1, 5-pentanedione has been synthesized by the condensation of acetophenone and benzaldehyde at different reaction conditions while stirring at $25^{\circ} \mathrm{C} .73 \%$ yield was obtained when reaction was conducted in Sodium hydroxide but $95 \%$ yield was achieved on conducting in Methyl-amine (entry 9, Table 1). Further, the synthesized 1, 3, 5-triphenyl-1, 5-pentanedione has been condensed with benzil and also cyclized in acidic as well as in basic media to get the product. $71 \%$ yield was obtained when condensed in mixture of potassium hydroxide and ethanol (entry 1 , Table 2) but condensation in conc. $\mathrm{H}_{2} \mathrm{SO}_{4}$ gave rise to $93 \%$ yield (entry 4 , Table 2 ). The progress of reaction was monitored by TLC (thin layer chromatography, Eluent; n-hexane/ethylacetate) visualizing under UV lamp and lodine bath.

Table 2: Summarized results for the synthesis of Methanone, 4 5-Diphenyl-3, 5-cyclopentadiene [diiyl]-diphenone (5) and 1, 2, 4-Triphenyl 1, 3-cyclopentadiene (6)

\begin{tabular}{|c|c|c|c|c|c|c|}
\hline \multirow{2}{*}{$\begin{array}{l}\text { Sr. } \\
\text { No }\end{array}$} & \multirow{2}{*}{$\begin{array}{l}\text { Reactant } \\
\mathbf{3}\end{array}$} & \multirow{2}{*}{$\begin{array}{l}\text { Reactant } \\
4\end{array}$} & \multirow[t]{2}{*}{ Reagents } & \multirow[t]{2}{*}{ Time } & \multicolumn{2}{|c|}{ Yield \% } \\
\hline & & & & & 5 & 6 \\
\hline 1 & & & $\mathrm{KOH}, \mathrm{C}_{2} \mathrm{H}_{5} \mathrm{OH}$ & $\begin{array}{l}\text { Refux, } \\
50^{\circ} \mathrm{C}\end{array}$ & 71 & 23 \\
\hline 2 & & & $\mathrm{Na}^{+} \mathrm{O}^{-} \mathrm{C}_{2} \mathrm{H}_{5}$ & $\begin{array}{l}\text { Stirring, } \\
25^{\circ} \mathrm{C}\end{array}$ & 78 & 12 \\
\hline 3 & & & Conc. $\mathrm{H}_{2} \mathrm{SO}_{4}$ & $\begin{array}{l}\text { Reflux, } \\
50^{\circ} \mathrm{C}\end{array}$ & 93 & 7 \\
\hline 4 & & & Conc. $\mathrm{H}_{2} \mathrm{SO}_{4}$ & $\begin{array}{l}\text { Reflux, } \\
50^{\circ} \mathrm{C}\end{array}$ & & 82 \\
\hline
\end{tabular}

\section{References}

1 Nudelman NS, Outumuro P (1982) Insertion of carbon monoxide into carbon-lithium bonds. A convenient one-step synthesis of 1, 2-diketone diaryl derivatives. J Org Chem 47: 4347-4348.

2 Cao S, Zhong S, Xin L, Wan JP, Wen C (2015) Visible-light-induced c=c bond cleavage of enaminones for the synthesis of 1,2-diketones and quinoxalines in sustainable medium. J Chem Cat 7: 1478-1482.

3 Cao H, Lei S, Li N, Chen L, Liu J, et al. (2015) Cu-Catalyzed selective C3formylation of imidazo[1,2-a]pyridine $\mathrm{C}-\mathrm{H}$ bonds with DMSO using molecular oxygen. J Chem Commun 51: 1823-1825.

4 Luo F, Pan C, Li L, Chen F, Cheng J (2011) Copper-mediated 
methylthiolation of aryl halides with DMSO. J Chem Commun 47: 5304 5306.

5 Qian J, Zhang Z, Liu Q, Liu T, Zhang G (2014) Dimethyl sulfoxide participating in copper(i) iodide-catalyzed cascade oxidation/ formylation reactions: The synthesis of $\alpha$-formylpyrroles from 2, 3 dihydro-1h-pyrroles. J Adv Synth Catal 356: 3119-3124.

6 Wu W, Su W (2011) Mild and selective ru-catalyzed formylation and fecatalyzed acylation of free $(\mathrm{N}-\mathrm{H})$ indoles using anilines as the carbony source. J Am Chem Soc 133: 11924-11927.

7 Kel'in AV (2003) Recent advances in the synthesis of 1, 3-diketones. J Curr Org Chem 7: 1691-1711.

8 Kel'in AV, Maioli A (2003) Recent advances in the chemistry of 1 , 3-diketones: Structural modifications and synthetic applications. J Curr Org Chem 7: 1855-1886.

9 Nishiyama Y, Kobayashi A (2006) Synthesis of 1, 4-diketones: Reaction of $\alpha$-bromo ketones with tetrakis(dimethylamino)ethylene (TDAE). J tetrahedron Letters 4: 5565-5567.

10 Kel'in AV and Kulinkovich OG (1996) J Synthesis 330.

11 Kel'in AV, Kulinkovich OG, Senin PV (1995) J Org Chem 31: 1060.

12 Raphael R (1955) Acetylenic compounds in organic synthesis. Butterworths Publications Ltd, London, England.

13 Heiba El, Dessau RM (1971) Oxidation by metal salts. VII. syntheses based on the selective oxidation of organic free radicals. J Am Chem Soc 93: 524.

14 Heiba El, Dessau RM (1972) Oxidation by metal salts. IX. formation of cyclic ketones. J Am Chem Soc 94: 2888-2889.

15 Marshall JA, Fanta WI, Roebke H (1966) Conjugate addition of methylmagnesium iodide to 10-methyl-1(9)-octal-2-one: An approach to the valeranone carbon framework. J Org Chem 31: 1016-1020.

16 House HO, Respess WL, whitesides GM (1996) J ibid 31: 3128.

17 Stork G, Hudrlik PF (1968) Isolation of ketone enolates as trialkylsilyl ethers. J Amer Chem Soc 90: 4462-4464.

18 House HO, Czuda L, Gall M, Olmstead HD (1969) Chemistry of carbanions. XVIII. preparation of trimethylsilyl enol ethers. J Org Chem 34: 2324-2336.
19 T.Kauffmann (1968) J Angew Chem 7: 540.

20 Kauffmann T, Berger D (1968) Aktivierung organischer verbindungen durch einführung von ubergangsmetallatomen, iv. dimerisierung von ketiminogruppen über ketimino-ubergangsmetallverbindungen. J Chem Ber 101: 3022-3030.

21 Maryanoff CA, Maryanoff BE, Tang R, Mislow K (1973) One-step synthesis of optically pure 1,2-ethanobis(sulfoxides)and phosphine oxides via the copper-promoted oxidative dimerization of chiral sulfinyl and phosphinyl carbanions. J Am Chem Soc 95: 5839-5840.

22 Miyashita M, Yanarni T, Yoshikoshi A (1976) New 1, 4-diketone synthesis using nitroolefins and trimethylsilyl enol ethers: A convenient regiospecific route to cyclopentenones. J Amer Chem Soc 98: 4679-4681.

23 Ballini R, Barboni L, Giarlo G (2003) Nitroalkanes in aqueous medium as an efficient and eco-friendly source for the one-pot synthesis of 1,4-diketones, 1,4-diols, $\delta$-nitroalkanols, and hydroxytetrahydrofurans. J Org Chem 68: 9173-9176.

24 Owsley DC, Nelke JM, Bloomfield JJ (1973) Synthesis of 1, 4 and 1, 5 diketones from N, N, N1, N1-tetramethyl diamides and organolithium reagents. J Org Chem 38: 901-903.

25 Potts KT, Cipullo MJ, Ralli P, Theodoridis G (1981) Ketene dithio acetals as synthetic intermediates: Synthesis of unsaturated 1, 5-diketones. J Am Chem Soc 103: 3584-3585.

26 Birch AJ (1947) J Chem Soc 1270.

27 Arigan ZS, Suchitiky H (1961) J Chem Soc 2242.

28 Krohnke F (1976) The Specific Synthesis of Pyridines and Oligopyridines. Synthesis 1: 1-24.

29 Constable EC, Cargill AMW (1995) Strategies for the assembly of homo and hetero-nuclear metallosupramolecules containing 2,2' : 6',2'-terpyridine metal-binding domains. J Chem Soc Dalton Trans 1615-1627.

30 Butler R, Mcdonald SJ (1995) Ferrocenylpyridines: A new synthesis of 4 '-ferrocenylterpyridine and the single crystal structure of a C3ferrocenophane, $\left[\left(\mathrm{n}-\mathrm{C}_{5} \mathrm{H}_{4} \mathrm{CHCH}_{2} \mathrm{C}(\mathrm{O})_{2}-\mathrm{C}_{5} \mathrm{H}_{4} \mathrm{~N}\right)_{2} \mathrm{CHC}(\mathrm{O})_{2}-\mathrm{C}_{5} \mathrm{H}_{4} \mathrm{~N}\right] \mathrm{Fe}$. Polyhedron 14: 529-539.

31 Hirsh SS, Bailey WJ (1978) Base-catalyzed alkylation of cyclopentadiene rings with alcohols and amines. J Org Chem 43: 4090-4094. 